\title{
What Do They Really Think? Assessing Student and Faculty Perspectives of a Web-based Tutorial to Library Research
}

\author{
Stephanie Michel
}

\begin{abstract}
Over the past thirty years, libraries have increasingly used forms of computer-assisted instruction (CAI) in place of librarians for basic instruction tasks. This study evaluates student and faculty perceptions of the Highlander Guide, a Web-based tutorial to library research. Overall, students (particularly those required to use it) and faculty reported positive views of the guide. Correlations drawn between student confidence in using the Web or conducting library research revealed that confident students reacted more favorably toward the Highlander Guide than average students did. In contrast to previous studies, the results of this study indicated that students and faculty were not strongly in favor of using the tutorial to replace traditional library instruction.
\end{abstract}

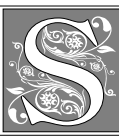

ince development of the modern computer in the 1950s, society has sought ways to use it in place of human labor. As early as the 1970s, although the microcomputer had not yet been developed, this statement held true for libraries, particularly in the area of bibliographic instruction. ${ }^{1}$ At a time when libraries were faced with budget cuts and reduced staffing, combined with growing demands for instruction, librarians began to search for alternative methods of providing instruction. ${ }^{2}$ In the midst of this situation, librarians recognized the potential for computers to provide interactive, individualized instruction without the intermediation of a librarian, and thus com- puter-assisted instruction (CAI) was born. $^{3}$

\section{Definition of CAI}

In 1971, Alan B. Salisbury defined computer-assisted instruction as "a man-machine interaction in which the teaching function is accomplished by a computer system without intervention by a human instructor. Both training material and instructional logic are stored in computer memory." 4 Salisbury's definition remains the authoritative definition for CAI today. In 1985, Patricia D. Arnott and Deborah E. Richards elaborated on Salisbury's definition by including a description of the functions performed by the program as well as some of its advantages:

Stephanie Michel is the Humanities Reference Librarian at the University of Oregon; e-mail: smichel@oregon.uoregon.edu. This article is based on work the author did as a Reference/Instruction Librarian at Radford University. 
The term computer-assisted instruction, or CAI, may apply to all instructional uses of the computer. More specifically, CAI means using the computer as an instructional tool: to present new information to the user, test a user's knowledge of the information previously presented, or allow her or him to discover new concepts. No instructor need be present, since the user interacts directly with the computer. All necessary directions are included within the lesson. The user is allowed to control the process by pressing keys to advance or review, all at his or her own pace. ${ }^{5}$

A variety of different programs have been used to create CAI tutorials, including: PLATO (Programmed Logic for Automatic Teaching Operation), the first programming package used to create CAI programs; HyperCard (for the Macintosh); Email; the World Wide Web; and other program-authoring software for both IBM and Macintosh computers. ${ }^{6-9}$

\section{History of CAI}

Although the 1970s are recognized as the beginning of "operational" CAI programs, the theoretical framework that paved the way for CAI was established in the 1950s. At this time, the behavioral psychologist B. F. Skinner supported a novel instructional approach called "programmed instruction," which was essentially the predecessor of CAI. Skinner theorized that "the real focus in education should be on consistent, immediate, positive reinforcement for appropriate behavior and for the attainment of delineated educational objectives." ${ }^{10} \mathrm{He}$ emphasized a "careful and sequential arrangement of teaching materials so that the 'learning experience will be presented at a size or rate that the student can handle, and so that prerequisite skills will have been mastered before more complex tasks are attempted.' "11

Using this behaviorist approach, several CAI tutorials were established as early as the 1960s. The PLATO system was used at the University of Illinois to teach a library skills course in the 1960s, which is still cited as among the most significant and successful ventures into CAI. ${ }^{12}$ The PLATO program also was used in the biology library at the University of Illinois in 1975 to teach students to use reference and bibliography collections and at the University of Delaware to teach basic library skills to freshmen English students. ${ }^{13,14}$ At both universities, the PLATO tutorials ran on a mainframe computer that was accessible from terminals across campus. ${ }^{15}$

\section{By the early 1980s, the necessary technological advancements had occurred that would make way for improved and enduring CAI.}

From 1972 to 1975, computer-assisted instruction was used at the University of Denver to teach traditional library skills and online searching techniques. ${ }^{16}$ This program has been described as a "wellestablished watershed" that had significant influence on later CAI programs. Although the program had ceased to exist by 1982, its founders concluded that CAI, "whether used for direct public access to information or for the more traditional teaching skills, is the wave of the future."17

Like the University of Denver program, by the end of the 1970s, many of the early CAI programs had ceased to exist. Citing reasons such as cost, inflexibility of time-sharing on the institution's mainframe, and lack of training or computer expertise on the part of librarians, most of the first CAI programs were eventually abandoned..$^{18}$ Although the first innovative programs were no longer in existence, they left their mark on the instruction world. CAI had been proven by pioneers in the field to be an effective form of providing instruction and needed only a boost in computer technology to resurge. ${ }^{19}$ By the early 1980s, the necessary technological advancements had occurred that would make way for improved and enduring CAI.

In the 1980s, the personal computer (PC) was developed: it was smaller, less expen- 
sive, easier to program, and well suited to library use. At the same time, librarians were becoming more knowledgeable about automated systems and beginning to assume responsibility for managing their own systems, which reduced the cost of computer operation. As a result of these advances, libraries now had direct control over access and cost for the programs, clearing the way for a resurgence of computer-assisted instruction in libraries..$^{20}$

\section{Why CAI?}

Computer-assisted instruction arose out of a situation in libraries wherein the resources were no longer sufficient to meet the needs of a growing and increasingly demanding population. In 1995, budget cuts helped to spur the creation of the Gateway to Information program at Ohio State Libraries to fill a need created by shortened library hours and a reduction in bibliographic instruction staff. ${ }^{21}$ This situation is not unique to Ohio State: due to a national trend in budget reduction in libraries across the country, many libraries are struggling to provide the same level or additional services with fewer resources..$^{22}$ As a result, many libraries have sought out alternative forms of instruction, such as CAI. ${ }^{23}$

Similarly, the CAI phenomenon resulted from libraries' inability to keep up with the tremendous demand for instruction. Several authors have cited an inability to keep up with consistently increasing demands on library instruction staff as a motivating factor in the creation of their CAI tutorials. ${ }^{24}$ This is particularly true as libraries continue to incorporate a growing number of electronic products into their collections. However, each new resource brings new demands on the instructional librarian to teach the use of a growing number of interfaces in addition to his or her usual instruction load. ${ }^{25}$ Thus, "[a]s the demand for advanced instruction increases, librarians search for optimal ways to minimize the time devoted to teaching basic library skills." 26 One means of accomplishing this is through the use of CAI tutorials.

\section{Advantages of CAl}

Computer-assisted instruction offers numerous advantages over all other formats of instruction. Evan Ira Farber outlined several inherent advantages to using computers, rather than humans, for repetitive forms of instruction: "A computer has infinite patience, no time constraints, does not take coffee breaks or fails to show up on weekends, and it can adapt to individual needs and requests." 27

Moreover, CAI offers a more individualized approach that allows each student to work at his or her own pace. ${ }^{28}$ It is consistent (providing each student the same information), flexible, and designed to meet the needs of students with various skill levels, and enables students to repeat or skip sections according to their own needs. ${ }^{29-31}$ Subsequently, it allows for "equalization in the levels of achievement" so that even if some students take longer than others to complete the program, every student should end up with a "roughly equivalent knowledge of the topic." 32

Because CAI does not require the direct intervention of a librarian to initiate, it has the potential to reach a greater number of students per semester. ${ }^{33}$ Meanwhile, it can be time-saving for librarians, freeing them to spend less time doing basic instruction and to use it elsewhere (for example, to help students with individual questions) and avoid burnout. ${ }^{34}$ Further, CAI allows librarians to provide a greater range of instruction, from basic skills to complex topics; and may use a variety of approaches, including humor, to convey the message. ${ }^{35}$ Finally, it also may alleviate routine questions. ${ }^{36}$

CAI programs are readily available, so students can use them according to their own schedule, whenever they are motivated to learn. ${ }^{37} \mathrm{CAI}$ also allows for greater interactivity between students and the computer, and is useful for providing hands-on simulations of online searching techniques. ${ }^{38}$ For foreign students, a CAI program may seem more approachable than a reference desk. ${ }^{39}$ As a result, CAI may enable libraries to reach segments of the user population who neither sign up 
for classes nor have the opportunity to participate in course-related instruction. ${ }^{40}$

Moreover, CAI methods have been proposed as a means of reaching a traditionally underserved population of library users-remote users. Janice Simmons-Welburn stated that "[w]e must acknowledge that many of our users would prefer not to leave their workstations, offices, labs, dorm rooms, or homes to do a certain amount of information seeking." ${ }^{41}$ Providing instruction to continuing education, distance education, and nontraditional students has continually posed a challenge to librarians. However, by using CAI programs, it is possible to deliver instruction to remote sites and to offer instruction during evening and weekend hours so as to more effectively reach these students at their convenience and point-of-need. ${ }^{42}$

Moreover, CAI programs are easy to update, particularly in Web format. They can offer automatic data collection so that right and wrong answers can be collected and the feedback immediately provided to users. ${ }^{43}, 44$ In addition, CAI may assist in the development of computer literacy by reducing the anxiety of working with microcomputers. ${ }^{45}$ Further, CAI may appeal to the current generation of students who already may be familiar with computers and help boost the library's image. ${ }^{46}$ Finally, students often show a more positive attitude toward CAI techniques. ${ }^{47}$

CAI programs on the Web offer several unique advantages. First, the Web is continuously available to anyone, anywhere, with a computer (Macintosh or IBM), a Web browser, and a network connection, enabling libraries to "extend services beyond the reference desk and the classroom and reach an audience not limited by physical proximity." ${ }^{48}$ It also allows the CAI designer to incorporate multimedia materials such as images, sound, or video into the tutorial to enliven the content. In addition, Internet access and Web browsers are free, cheap, or already available to most members of an academic community. ${ }^{49}$ Hypertext documents are easy to create and update, and links may be easily provided to point users toward relevant outside material..$^{50}$ Finally, the associative nature of the Web allows students to create "individual pathways to problem solving" by interacting directly with the computer to become independent learners. ${ }^{51}$ Thus, the Web may foster critical thinking and offer a more challenging and varied learning experience for the student. ${ }^{52}$

\section{Disadvantages of CAI}

Although computer-assisted instruction techniques offer numerous advantages over other formats of library instruction, these methods are not infallible. CAI programs have been criticized for several reasons. First, they are expensive, requiring a significant investment in costly software and hardware in addition to the cost of the librarian or programmer's time. ${ }^{53}$ Second, they require substantial preparation time, generally one hundred to two hundred hours for each hour of CAI ${ }^{54}$ Further, CAI, particularly in non-Web formats, is limited to the number of terminals or computers available with access to that program. ${ }^{55}$

In addition, CAI may reduce personal contact between student and librarian, which lessens the opportunity to receive feedback, ask questions, or develop a relationship..$^{56}$ This method of instruction also may exclude students who are unfamiliar or uncomfortable with using computers, as well as anyone who requires special attention. ${ }^{57}$ Furthermore, most people read 20 to 30 percent slower and less accurately on a computer screen than from a printed page, which reduces the program's effectiveness. Prolonged reading from a computer monitor also may result in eyestrain. ${ }^{58}$ And depending on the format, CAI may not be easily accessible for review. One instructor warns his students: "[y]ou can't mark this program with a yellow highlighter or study it over lunch." ${ }^{\prime 59} \mathrm{How}$ ever, the ability to print out information may help alleviate this problem.

Use of the Web for CAI can pose some unique problems. The Web is often slow, particularly during daytime hours when the program is most likely to be accessed. 
Although the Web has the capability to include graphics, sound, and video clips, not all users have the necessary hardware or plug-ins to access these files. Lastly, it is much easier to leave a Web tutorial simply by pressing one button and thus ending the instruction, whereas other forms of CAI might require more thought and deliberate action to exit the program. ${ }^{60}$

\section{CAl versus Traditional Instruction}

Several studies have been conducted to compare the effectiveness of computer-assisted instruction to more traditional instructional methods. In 1989, Central Missouri State University evaluated the effectiveness of a library tour written in the Utah PILOT (Programmed, Inquiry, Learning, or Teaching) language, as compared to a traditional library tour. ${ }^{61}$ At Western Michigan University, a Hypercard CAI program was compared to traditional workbook instruction. ${ }^{62}$ Librarians at UCLA's Louise M. Darling Biomedical Library compared a lecture-type presentation to a CAI module for instruction to three hundred undergraduate biology students. ${ }^{63}$ Lastly, at the University of Albany, librarians compared a Web-based interactive tutorial to traditional in-class instruction, which involved a combination of lecture and hands-on activities. ${ }^{64}$ In every study, CAI was found to be as effective or more effective than the more traditional forms of instruction. ${ }^{65,66}$ Further, students preferred the CAI method of instruction, noting that it was easy to use, interactive, and self-paced. ${ }^{67}$ In every case, based on the results of the survey, the universities decided to replace traditional instruction with CAI.

\section{Description of the Environment}

Radford University is a state-sponsored university of about 10,000 undergraduate and graduate students located in southwestern Virginia. In 1997, the library staff developed a brief library tutorial outlining basic library services and resources. However, in 1998, the instruction librarians perceived a need to expand on this preliminary tutorial in order to include more information on how to conduct research, including finding, evaluating, and citing information. Two instruction librarians and the technology manager prepared a grant proposal and were awarded a Radford University grant that provided the necessary software and release time to work on the project.

During the summer of 1998, the preliminary tutorial was replaced with an expanded and enhanced tutorial modeled after James Madison University's tutorial entitled Go for the Gold. The tutorial contains seven sections: Orientation to McConnell Library, Develop a Research Strategy, Finding Information Resources, Searching Electronic Databases, Using Internet Resources, Evaluating Information Sources, and Giving Credit: Citing Sources. The developers intended to have a quiz at the end of each section to test the user's knowledge of the subject matter; due to time constraints, at this time, only two quizzes are available. The graphics used in the tutorial reflect a Scottish theme, and the tutorial is named the Highlander Guide (after the Radford University mascot, the Highlander).

In the planning stages, the Highlander Guide was intended for use by any undergraduate student, graduate student, or faculty member, although it was especially designed for use with University 100 (an introduction to the university course taken by most freshmen), English 102 (a basic freshman writing course), and for off-campus students at the university's two extended campus locations. The tutorial can be found online at <http:/ / lib.runet.edu/hguide/ $>$.

\section{Methodology}

In spring of 1999, the instruction librarians wished to evaluate student and faculty perceptions of the Highlander Guide. A student questionnaire containing thirtyone questions was devised, based on examples of survey forms printed in Evaluating Library Instruction: Sample Questions, Forms, and Strategies for Practical Use.$^{68}$ The survey included questions about the student's computer experience, comfort 
level using computers, prior library use, prior library instruction, and comfort level using the library to find information. In addition, students were asked how often they had used the Highlander Guide and were presented with twelve questions using a Likert scale, ranging from "strongly agree" to "strongly disagree," which asked them to rate the Highlander Guide based on organization, ease of use, assistance in their research, and overall experience. Finally, they were given the opportunity to answer three short-answer questions about the most and least helpful aspects of the Highlander Guide and how it could be improved. After development, the survey was pretested on students who worked in the library's computer lab for accuracy and clarity.

A separate faculty questionnaire also was devised, based on the student questionnaire, and examples taken from Evaluating Library Instruction. Faculty were asked about prior experience with library instruction, perceptions of their students' research skills, prior use of the Highlander Guide, and attitudes toward the guide. Like the questions in the student questionnaire, questions in the faculty questionnaire were based on a Likert scale, with responses ranging from "strongly agree" to "strongly disagree." Faculty also were given four short-answer questions that asked them to state the most and least helpful aspects of the guide, how it could be improved to assist in classroom instruction, and how it could be modified to be more relevant to their needs.

The audience for this study was composed of English 102 students and faculty. During library instruction sessions earlier that semester, many sections of English 102 had been introduced to the Highlander Guide as a source for further information about library research. Further, one section of English 102 had been required to use part of the Highlander Guide as an assignment in their class. The instruction librarians identified English 102 courses where it could be positively determined that the Highlander Guide had been presented during library in- struction, and surveys were sent to those faculty members in mid-March. A total of six faculty members, representing twelve sections of English 102, received surveys.

\section{Results}

A total of 145 surveys were returned-141 student surveys and four faculty surveys. The preliminary questions asking for information about student computer usage produced some interesting results. Of the students surveyed, 78.7 percent reported owning a PC and 97.9 percent reported using a computer daily or weekly in the past six months. However, only 46 percent of those students stated their confidence in using a computer to be very good or excellent. The primary purposes for using a computer were word processing $(88.6 \%)$, surfing the Web $(88.6 \%)$, or class assignments (not including word processing) $(75.9 \%)$. Although 85.8 percent of students reported using the Web daily or weekly, only 46.8 percent rated their confidence in using it as very good or excellent.

Further, students were not frequent library users. Only 31.2 percent reported using the library daily or weekly, compared to 66.7 percent who used it occasionally. Overwhelmingly, students reported using the library to obtain information for research and/or class assignments $(93.6 \%)$, followed by studying for courses $(54.6 \%)$, and using reserve materials $(44.7 \%)$. The majority of students $(83.6 \%)$ had asked at least one question at the reference desk, and most students were not confident of their ability to find a list of resources on a topic of their choice in the library. Only 7.88 percent rated their ability to find information as very good or excellent, whereas the majority (53.1\%) rated their ability as average.

On questions related to their use of the Highlander Guide, forty-seven students $(33.3 \%)$ reported having used it three or more times and thirty-four $(24.1 \%)$ had never used it. Of those students who had used it, thirty-two (22.6\%) had used it for thirty minutes or more and fifty-nine $(41.8 \%)$ had used it for ten to thirty minutes. 
As table 1 shows, student reactions to the Highlander Guide were mostly positive. The majority of students surveyed agreed or strongly agreed that the guide was easy to use, was clearly organized, and assisted them in finding books or magazines in the library. Just over half (56.1\%) the students reported learning valuable information from the guide, and 50.4 percent preferred using it to attending a formal library instruction session. Seventyfour students (62.2\%) described their over-

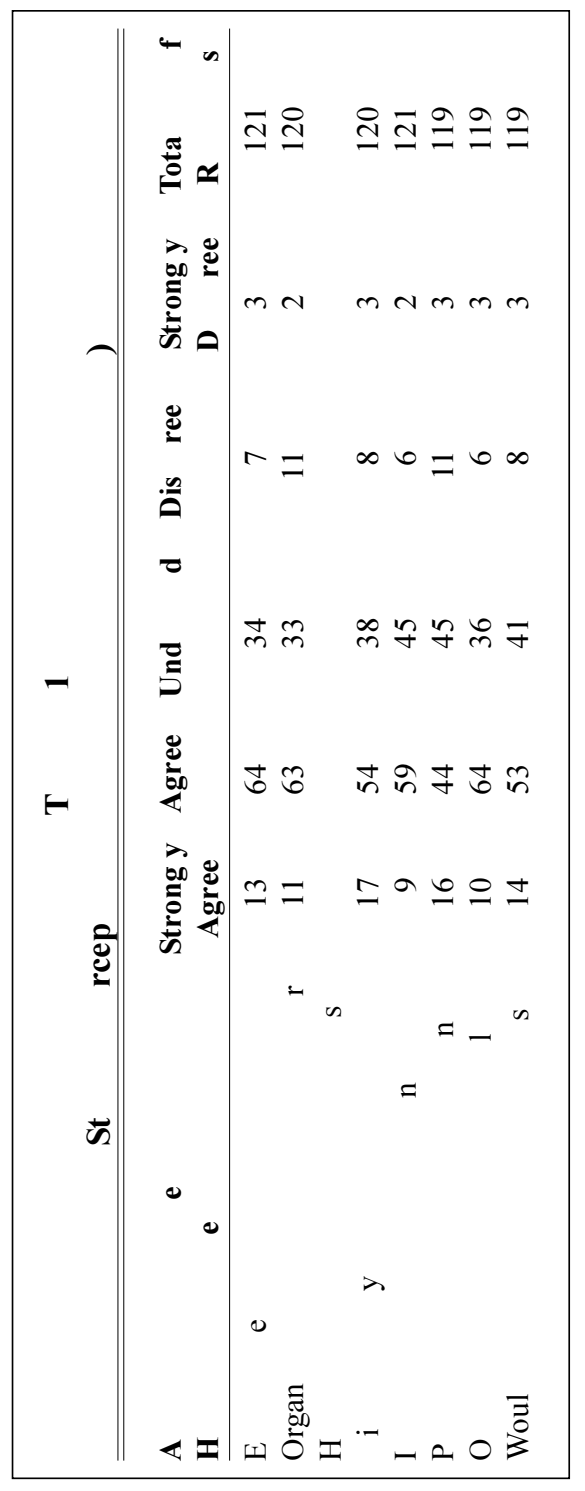

all experience with the Highlander Guide as successful, and sixty-seven (56.3\%) agreed or strongly agreed that they would recommend it to other students.

In the short-answer questions, students varied in their opinions of the most helpful aspect of the Highlander Guide. Many students found the description of searching for books or periodicals most helpful; others appreciated the information on interlibrary loan (ILL). Several students remarked that the guide was easy to use and enjoyed the ability to use it from their own computer. One student cited "the quickness and simplicity of using it," and another stated that "the Highlander Guide provides a fair amount of information to a student without being consumed by too much information."

For the least helpful aspect, some students listed "confusing" or "frustrating," or the inclusion of unnecessary information. One student said the tutorial provided "too much information not exactly relating to topic." In answer to the question What would make the Highlander Guide more relevant to your needs? students requested that it be made clearer or less confusing. One student said that there were too many ways to get to too many things; another wanted more updating. Two students wished it would "do my work for me."

Faculty responses to the Highlander Guide were overwhelmingly positive. In the "Perceptions of Students' Skills" section of the questionnaire, three out of four faculty members strongly agreed with the statement that "incoming freshmen do not have the necessary skills to use an academic library." All four faculty members strongly agreed that it is important for students to know how to use a library. Three faculty members had used the Highlander Guide at least once, with two of them using it for between ten and thirty minutes and one using it for between thirty and sixty minutes.

Faculty also demonstrated positive opinions of the Highlander Guide, as seen in table 2 . All the faculty members agreed or strongly agreed that it was easy to use 
and clearly organized. Three faculty members felt that it provided a valuable learning experience for their students; one was undecided. Only one faculty member preferred students to use the Highlander Guide to a formal instruction session; the other three disagreed. In assessing their overall experience, two faculty members were undecided and two agreed or strongly agreed that their experience was successful. Similarly, two faculty members were undecided and one agreed that their students' overall experience was successful. After using the Highlander Guide, two faculty members agreed that students seemed more knowledgeable about how to use the library. All four faculty members agreed or strongly agreed that they would recommend the guide to other faculty members.

For the short-answer questions, faculty reported the most helpful aspect of the Highlander Guide to be the maps of the library, keyword searches, citation information, and information on evaluating sources. Responses to the least helpful aspect included too much use of jargon and the quizzes that have not yet been posted. One faculty member suggested adding a sample student paper to the guide to model documentation. Other comments included "thanks for creating and evaluating this great tool" and a faculty member who had never used the Highlander Guide stated "now that I am aware of the Highlander Guide, I plan to make use of it in future classes I teach at RU, especially English 102."

Fifteen surveys were received from the English 102 class that had been required to use the Highlander Guide for an assignment. The responses from this "required" group provided an interesting contrast to students in the other sections of English 102. In this class, 53.3 percent of students had used the Highlander Guide three or more times, compared to the overall total of 33.3 percent for the other students surveyed. For total time spent using the guide, 46.7 percent of students in this section had used it for thirty or more minutes, compared to 22.6 percent overall.

Students in this section of English 102, who had had more frequent exposure to the Highlander Guide, gave it much higher results, as seen in tables 3 and 4 . Of these students, 80 percent agreed or strongly agreed that it was easy to use, compared to 63.6 percent overall (table 4).

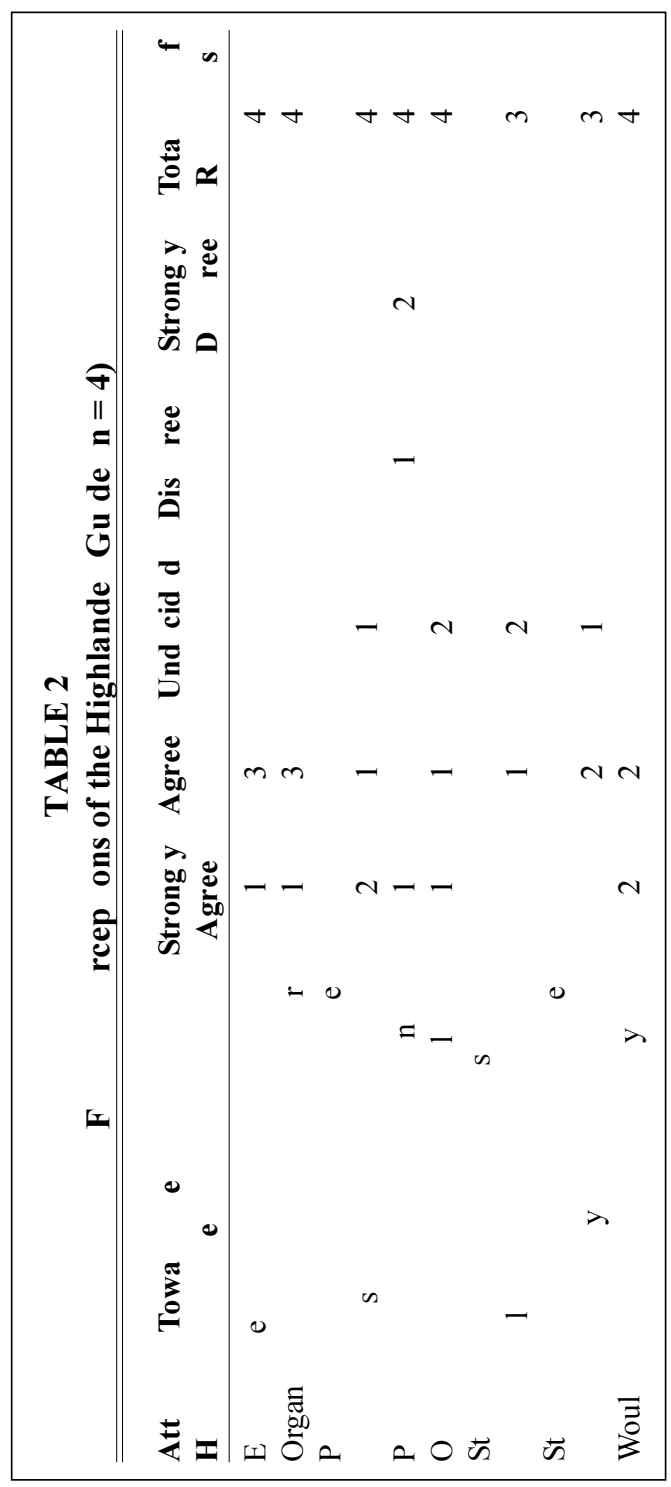


TABLE 3

Perceptions of Students Required to Use the Highlander Guide $(n=15)$

\section{Attitudes Toward the Highlander Guide}

\section{Easy to use}

Organization of information was clear

Helped to find books and magazines

in the library

I learned valuable information

Prefer to formal instruction session

Overall experience was successful

Would recommend to other students

\author{
Strongly Agree Undecided Disagree \\ Agree
}

$\begin{array}{rrrl}4 & 8 & 3 & \\ 3 & 11 & 1 & \\ & & & 1 \\ 3 & 7 & 4 & \\ 1 & 10 & 4 & 1 \\ 1 & 6 & 7 & \\ 2 & 11 & 2 & \\ 3 & 8 & 4 & \end{array}$

*The option of "strongly disagree" received no responses and has been omitted from this table.

With regard to clarity of information, 93.3 percent of students in this section agreed or strongly agreed that the guide was clear, compared to 61.7 percent overall. Moreover, the guide helped 66.7 percent of these students to find books and magazines in the library, compared to 59.2 percent overall. Further, 73.3 percent of students reported they learned valuable information from it, compared to 56.2 percent overall. In rating overall experience with the Highlander Guide, 86.7 percent of students in this section agreed or strongly agreed that it was successful, compared to 62.2 percent overall; and 73.3 percent of these students agreed or strongly agreed that they would recommend it to other students, compared to 56.3 percent overall. The only question to which student responses from this section mirrored the overall responses was whether students preferred using the Highlander Guide to attending a formal library instruction session: 46.7 percent of students in the "required" section agreed or strongly agreed with this statement, compared to an overall response of 50.4 percent.

Student responses to short-answer questions in this in this section demonstrated that they found the information on ILL, finding periodicals, and "the instructional ideas about research" most helpful. The least helpful aspect was the "thick" writing. Suggestions for making the guide more useful to students in- cluded "continue current progress" and "make it more clear."

In addition, correlations were drawn between students' perceptions of the Highlander Guide and their confidence in using the Web, or in their self-perceived ability to find resources on a topic of their choice in the library, as shown in table 5. Overall, the fifty-five students who reported their confidence in using the Web

\section{For almost every response, students in the "required" group had a significantly more favorable reaction to the Highlander Guide than the other students did.}

as very good/excellent gave the guide higher ratings. Sixty-nine percent of these students agreed or strongly agreed that the guide was easy to use, compared to an overall score of 63.6 percent; 63.6 percent of these students agreed or strongly agreed that it helped them find books and magazines, compared to 59.2 percent overall; and 54.5 percent preferred it to library instruction, compared to 50.4 percent overall. Lastly, 69 percent of the students in this category agreed or strongly agreed that their overall experience was successful, compared to 62.2 percent overall. By comparison, of the sixty-five students who rated their Web confidence as poor/fair or average, 61.5 percent agreed or strongly agreed that the Highlander 


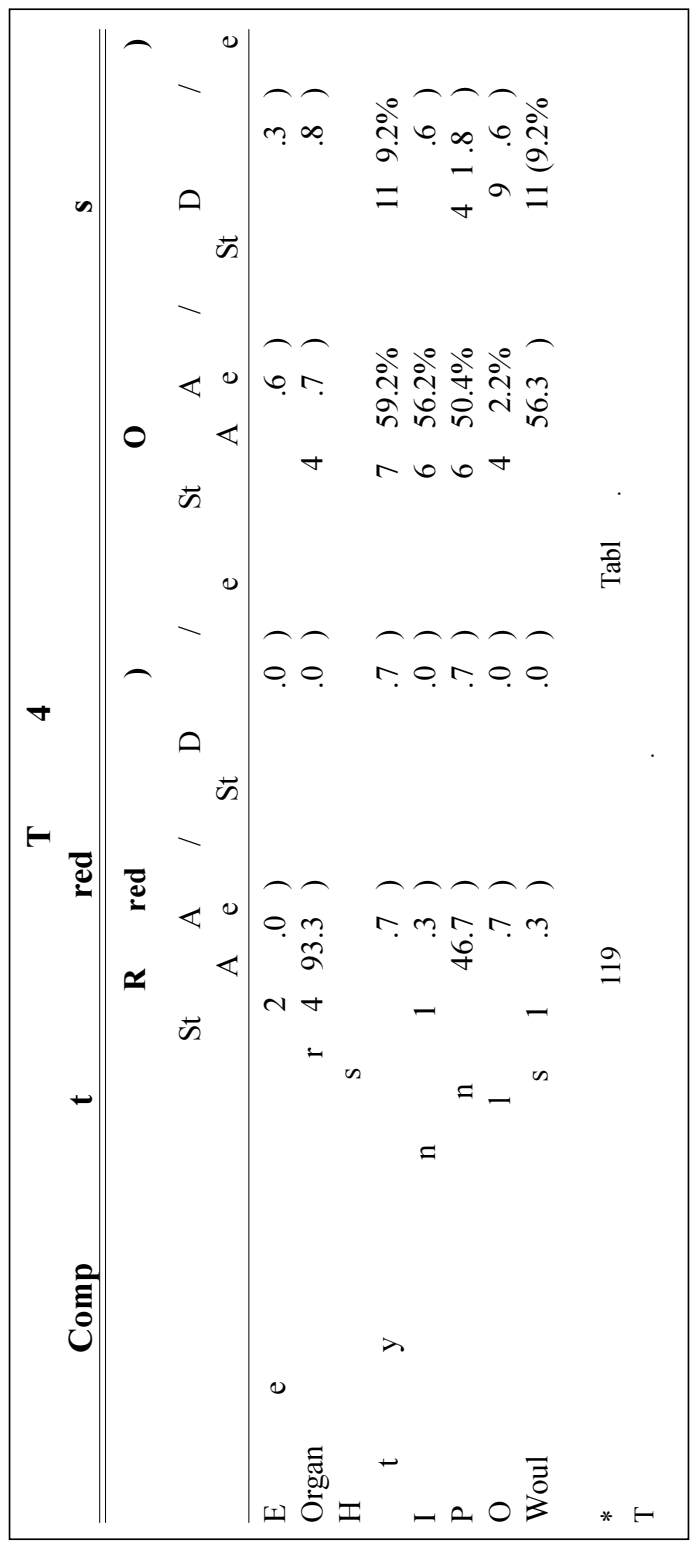

75.7 percent agreed or strongly agreed that it was easy to use, compared to 63.6 percent overall; 64.9 percent said it helped them find books or magazines, compared to 59.2 percent overall; and 59.5 percent preferred using it to traditional instruction, compared to 50.4 percent overall. In terms of overall experience, 78.4 percent of these students agreed or strongly agreed that their overall experience was successful, compared to 62.2 percent of all students surveyed. By comparison, of the eighty-four students who rated their ability to find resources in the library as poor/fair or average, 58.3 percent agreed or strongly agreed the Highlander Guide was easy to use; 56 percent reported that it helped them find books or magazines; 46.4 percent preferred it to traditional instruction; and 54.8 percent reported their overall experience as successful.

\section{Discussion}

Perhaps the most surprising finding of this study was the underwhelming majority of students who preferred to use the Highlander Guide rather than attend a traditional library instruction session. In the literature, the results usually showed students definitely preferring an online tutorial or other self-paced format to traditional library instruction. ${ }^{69,70}$ However, this study showed only 50.4 percent of students and 25 per-

Guide was easy to use; 55.4 percent said it helped them find books or magazines; 49.2 percent preferred it to library instruction; and 55.4 percent reported an overall successful experience with it.

Based on their self-reported ability to find resources on a topic of their choice in the library, students who reported themselves as very good/excellent also gave the Highlander Guide higher ratings, as seen in table 6. Of these thirty-seven students, cent of faculty preferring or strongly preferring the Highlander Guide to traditional instruction. Both students and faculty seemed to be ambivalent and not strongly in favor of this substitution.

For faculty, the answer may lie in the Highlander Guide's content. The instruction librarians usually tailor an instruction session to the content of the course, which ensures that the sources and search examples demonstrated are relevant to 


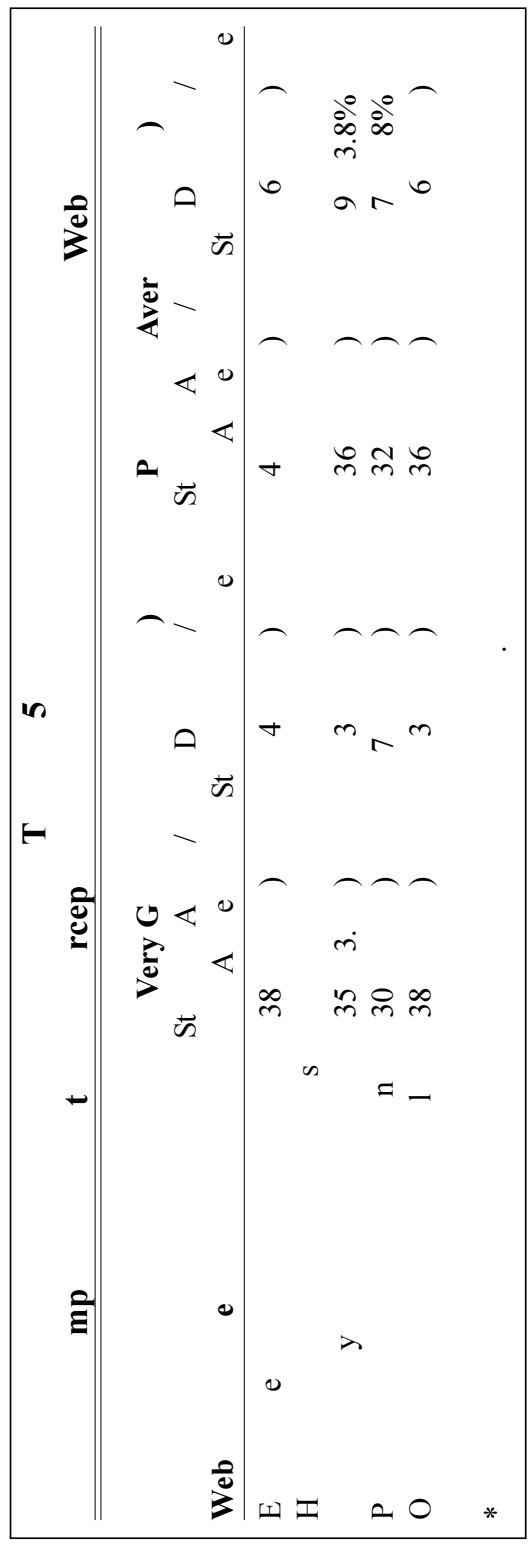

the students in that course. However, the Highlander Guide is devised to be used by anyone, so its content is more general and may or may not meet a particular course's objectives.

However, it is not as easy to explain the students' response. It was hypothesized that students would prefer the more interactive, self-paced nature of the online tutorial. For the most part, undergraduates are familiar with computers and the Web, and it was assumed that they would be receptive to learning new information using this medium. In the author's experience teaching traditional library instruction sessions, students are not always open to receiving information in a traditional instruction forum. Evidently, they either enjoyed the traditional methods more than was readily apparent during the instruction session or were not accustomed to the format of the online tutorial. Perhaps they were uncomfortable with learning that particular content from the computer or the Highlander Guide's current organization and wording were not conducive to their learning. Or, possibly, like faculty, students prefer the more specialized, individualized nature of an instruction session organized and presented to their individual class, rather than the more general nature of an online tutorial.

Some of the correlations discussed in this article also provided an interesting insight into student perspectives of the Highlander Guide. In particular, students who had been required to use the guide had a significantly more positive reaction to it than did the total of all the English 102 sections surveyed. Students in the "required" group used the guide more frequently and for a longer period of time than the other English 102 students did and thus had a greater period of time in which to form their opinions. Moreover, it is possible that because their instructor required them to use the Highlander Guide, these students were influenced by the faculty endorsement and thus perceived the guide to be more important or useful to their research. For almost every response, students in the "required" group had a significantly more favorable reaction to the Highlander Guide than the other students did. The only exception was the question about preferring it to traditional library instruction. In this case, students in the "required" group responded less positively than the other students did, but the difference was not significant. That answer is particularly telling because these students had more opportunity to interact with the Highlander Guide, but only 


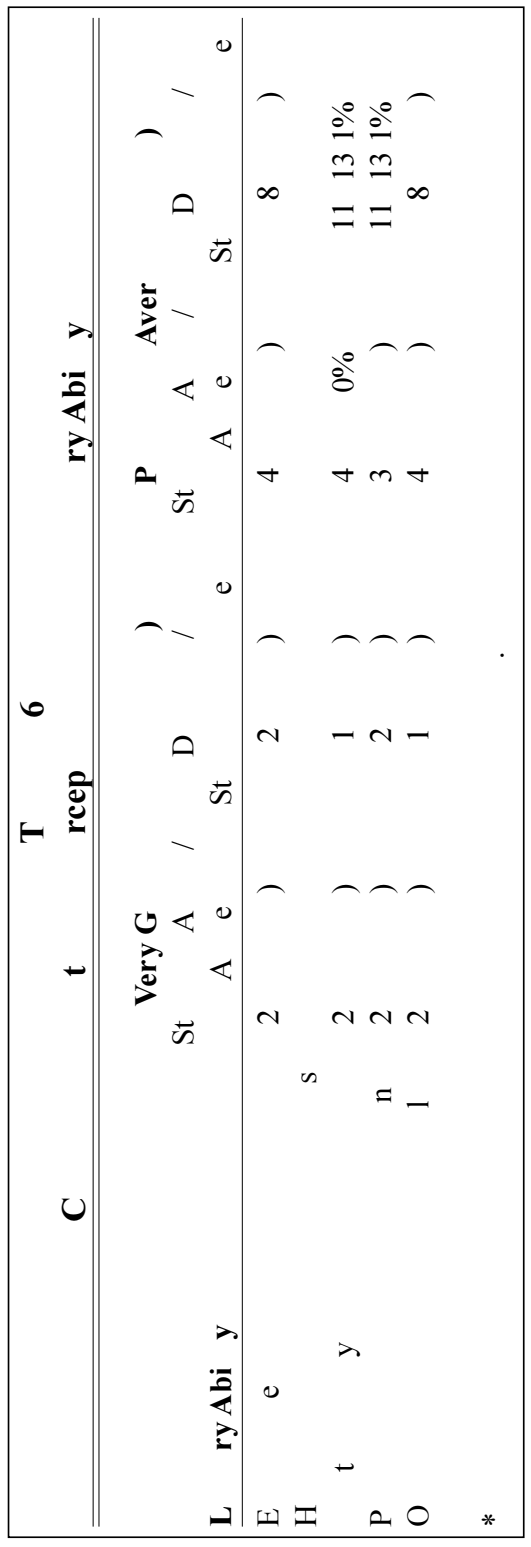

slightly less than half preferred the tutorial to traditional library instruction.

The other correlations demonstrate how a student's prior experience could influence his or her opinion of the Highlander Guide. The students' statement of confidence in using the Web may have influenced their opinions of the guide. Students who reported a strong degree of confidence in using the Web responded more positively than average in all aspects of using the Highlander Guide, suggesting that unfamiliarity with Web format or with using a computer did not influence their opinion of the tutorial. Conversely, students who did not report themselves as confident users of the Web answered slightly less positively than average on all points of using the Highlander Guide. It could be inferred that part of these students' reactions to the Highlander Guide could be related to lack of familiarity with a Web browser or conventions of using a computer and navigating on the Internet.

Further, the correlation between student confidence in using the library to find information and their opinions of the Highlander Guide produced interesting results. Students who felt confident in using the library responded significantly more positively to all Highlander Guide questions than average, whereas students who indicated a lower level of confidence in using the library were less positive about their Highlander Guide experience. This suggests that students already familiar with the material presented in the Highlander Guide may have found the guide easier to use because the topics may have been a review, rather than new information. This also may reinforce some student comments that the Highlander Guide included too much jargon, which might be familiar to students accustomed to library research, but less evident to those just learning how to use the library.

The results of the faculty survey reflected expectations that faculty on the whole would be positive about using the Highlander Guide. The most remarkable result was the response to the question about use of the Highlander Guide as opposed to traditional library instruction, where the faculty were strongly against this substitution. As mentioned previously, this may be due to the more personalized, specialized nature of courserelated instruction sessions. It also is possible that this response stems from faculty unfamiliarity with using computers or the Web, which was not measured on the faculty survey, or hesitance in adopting new methods of instruction. 
It should be noted that several circumstances may have influenced the results of this survey. First, not all students answered every question. For each question on the student's perception of the Highlander Guide, at least twenty students did not respond. Of those students who did respond, many who reported in their comments that they had not used the Highlander Guide answered "undecided" to every question, which influenced the results. Further, some students misinterpreted the Likert scale used on the questionnaire. For the questions about the Highlander Guide, students were instructed to circle a number between 1 and 5 , with 1 meaning "strongly agree" and 5 "strongly disagree." Some students who consistently circled numbers representing disagree or strongly disagree listed positive comments about the Highlander Guide, leading to the belief that these students had intended to agree or strongly agree with these statements.

Finally, some students did not seem to know what they were evaluating. Many commented that they either had not used the Highlander Guide or did not know what it was. Others rated it, but their comments reflected that they believed they also were rating periodical databases, the library catalog, or the library's Web site.

\section{Conclusions and Suggestions for Future Research}

There are several methods by which this survey could be improved in its next iteration. First, it might be sent out earlier in the semester, closer to the time of the initial instruction. This survey was sent out and completed near the end of the semester, when some of the content of that instruction session may have been forgotten. Delivering the survey earlier in the semester would poll students while the instruction was fresh in their minds and perhaps would help to remind them that the tutorial was available for their use.

The results of this survey also suggest that this online tutorial should be promoted more actively. Even though the Highlander Guide had been mentioned during an instruction session, many students were unaware of its existence or purpose. This suggests that more attention should be given to the guide during the instruction session to help students remember that it is available. Further, the Highlander Guide should be mentioned more prominently on the library's Web page so that students can more easily find this resource. Since this survey was conducted, the library has completed a major revision to its Web page. Previously, the link on the library's Web page to the tutorial read only "Highlander Guide," which many students did not recognize as an online tutorial. In the revision, the link reads "Highlander Guide to the Library" and a pop-up menu in the center of the screen provides the following description: "An online tutorial to library research including: finding information, searching databases, evaluating resources, citing sources, and more ..."

The survey indicates that students are mostly positive about using the Highlander Guide, although they are ambivalent about using it in place of traditional library instruction. In particular, students required to use the tutorial as a part of their course were very favorable, suggesting that it was a positive addition to this course. In addition, students who were very confident in their knowledge of the Web or in using library resources also expressed very positive views of the Highlander Guide, suggesting that it may be especially suited to these populations.

Based on the results of this survey, further revisions should be made to the Highlander Guide. Student comments suggest that the wording or navigation used in the tutorial may be confusing; perhaps these issues can be resolved in future revisions. Further, during the next revision, it would be a good idea to conduct usability testing of the Highlander Guide with a group of students so as to get immediate feedback about their perceptions and concerns.

A follow-up survey of the Highlander Guide will likely be conducted in the next few years to see how perceptions and attitudes toward it have changed over time. 
Moreover, a search of the literature revealed that there are relatively few current articles assessing the effectiveness or perceptions of current Web-based online tutorials, which suggests that this is another area in need of further research. Finally, more research is needed to evaluate students' preference for online tutorials as compared to traditional instruction because the results of this survey seem to differ from results previously reported in the literature.
Ultimately, this survey suggests that an online tutorial can be an effective supplement to, and possibly a replacement for, traditional library instruction. When designed well and adequately promoted in instruction sessions and through the library's Web page, an online tutorial can assist students or faculty at any time of day or night, at their own pace, to focus on learning a specific skill or developing an overall knowledge of library research.

\section{Notes}

1. Mitsuko Williams and Elisabeth B. Davis, "Computer-Assisted Instruction: An Overview," in Theories of Bibliographic Education: Designs for Teaching, ed. Cerise Oberman and Katina Strauch (New York: R. R. Bowker, 1982), 171-91.

2. Neosha Mackey, Charlotte Dugan, Willa Garrett, and C. Lynne Freeman, "Teaching with HyperCard in Place of a Textbook," Computers in Libraries 12 (Oct. 1992): 22-26; Fred Roecker, "Successful Research Using the Gateway to Information: Meeting the Challenge of User Independence," in The Upside of Downsizing: Using Library Instruction to Cope, ed. Cheryl LaGuardia, Stella Bentley, and Janet Martorana (New York: Neal-Schuman, 1995), 191-202.

3. Judith M. Pask, "Computer-Assisted Instruction for Basic Library Skills," Library Software Review 7 (Jan./Feb. 1988): 6-11.

4. Alan B. Salisbury, "An Overview of CAI," Educational Technology 11 (Oct. 1971): 48.

5. Patricia D. Arnott and Deborah E. Richards, "Using the IBM Personal Computer for Library Instruction," Reference Services Review 13 (spring 1985): 69-72.

6. Williams and Davis, "Evaluation of PLATO Library Instructional Lessons," Journal of Academic Librarianship 5 (Mar. 1979): 14-19.

7. Gwynneth T. Heaton, Sophia Kazuba, and Dan D'Agostino, “A HyperCard Program to Assist Users at a Self-help Periodicals Information Center," Technical Services Quarterly 11, no. 2 (1993): 55-70; Eric T. Rumsey, "HyperCard for Bibliographic Instruction: Teaching IBM Computer Use, Plus Much More," Computers in Libraries 12 (June 1992): 43-45.

8. Ann Jensen and Julie Sih, "Using E-mail and the Internet to Teach Users at their Desktops," Online 19 (Sept./Oct. 1995): 82-86.

9. Carol Anne Germain, Trudi E. Jacobson, and Sue A. Kaczor, "A Comparison of the Effectiveness of Presentation Formats for Instruction: Teaching First-year Students," College $\mathcal{E} R e-$ search Libraries 61 (Jan. 2000): 65-72.

10. Williams and Davis, "Computer-Assisted Instruction," 173.

11. Ibid.

12. Ibid.

13. Williams and Davis, "Evaluation of PLATO."

14. Arnott and Richards, "Using the IBM Personal Computer for Library Instruction."

15. Ibid.

16. Pask, "Computer-Assisted Instruction for Basic Library Skills."

17. Williams and Davis, "Computer-Assisted Instruction," 180-81.

18. Pask, "Computer-Assisted Instruction for Basic Library Skills."

19. Williams and Davis, "Computer-Assisted Instruction," 171-91.

20. Pask, "Computer-Assisted Instruction for Basic Library Skills."

21. Roecker, "Successful Research Using the Gateway to Information."

22. Otis Chadley and Jacquelyn Gavryck, "Bibliographic Instruction Trends in Research Libraries, Research Strategies 7 (summer 1989): 106-13.

23. Dorothy F. Davis, "A Comparison of Bibliographic Instruction Methods on CD-ROM Databases," Research Strategies 11 (summer 1993): 156-63; Laura Manzari and Ellen McCartney, "Librarian Attitudes toward the Use of a Self-paced BI Program," Research Strategies 12 (winter 1994): 33-44; Marjorie Melick, "Changing to a Hypertext-based Library Instruction Program Using Inexpensive Software for IBM Compatibles," Computers in Libraries 14 (Nov./Dec. 1994): 3538; Marsha Miller, "Self-paced Tours in the Electronic Library," Research Strategies 13 (fall 1995): 219-34; Pask, "Computer-Assisted Instruction for Basic Library Skills"; Patricia Fravel Vander 
Meer and Galen E. Rike, "Multimedia: Meeting the Demand for User Education with a Selfinstruction Tutorial," Research Strategies 14 (summer 1996): 145-58.

24. Lana S. Dixon, Marie Garrett, Rita Hoyt Smith, and Alan Wallace, "Building Library Skills: Computer-Assisted Instruction for Undergraduates," Research Strategies 13 (fall 1995): 196-208; Germain, Jacobson, and Kaczor, "Comparison of the Effectiveness of Presentation Formats for Instruction"; Bruce A. Leach, "Computer-based CD-ROM Tutorials-Providing Effective Ondemand Instruction," CD-ROM Professional 6 (July 1993): 113-17; Mackey, Dugan, Garrett, and Freeman, "Teaching with HyperCard in Place of a Textbook."

25. Linda Creanor, Helen Durndell, and Carol Primrose, "Library and Study Skills Using Hypertext: The TILT Experience," New Review of Hypermedia and Multimedia 2 (1996): 121-47; Vander Meer and Rike, "Multimedia."

26. Vander Meer and Rike, "Multimedia," 146.

27. Evan Ira Farber, "Plus Ça Change...," Library Trends 44 (fall 1995): 435.

28. Pask, "Computer-Assisted Instruction for Basic Library Skills."

29. Joan Kaplowitz, and Janice Contini, "Computer-Assisted Instruction: Is It an Option for Bibliographic Instruction in Large Undergraduate Survey Classes?" College \& Research Libraries 59 (Jan. 1998): 19-27; Pask, "Computer-Assisted Instruction for Basic Library Skills"; Harold B. Shill, "Bibliographic Instruction: Planning for the Electronic Environment," College \& Research Libraries 48 (Sept. 1987): 433-53.

30. Creanor, Durndell, and Primrose, "Library and Study Skills Using Hypertext"; Pask, "Computer-Assisted Instruction for Basic Library Skills"; Ann Turner, "Computer-Assisted Instruction in Academic Libraries," Journal of Academic Librarianship 15 (Jan. 1990): 352-54.

31. Andrew Cox, "Hypermedia Library Guides for Academic Libraries on the World Wide Web," Program 24 (Jan. 1996): 39-50; Creanor, Durndell, and Primrose, "Library and Study Skills Using Hypertext"; Gregg Richardson, "Computer-Assisted Library Instruction? Consider Your Resources, Commitment, and Needs," Research Strategies 12 (winter 1994): 45-55.

32. Donna E. Bourne, "Computer-Assisted Instruction, Learning Theory, and Hypermedia: An Associative Linkage," Research Strategies 8 (fall 1990): 164.

33. Richardson, "Computer-Assisted Library Instruction?"

34. Creanor, Durndell, and Primrose, "Library and Study Skills Using Hypertext"; Pask, "Computer-Assisted Instruction for Basic Library Skills."

35. Creanor, Durndell, and Primrose, "Library and Study Skills Using Hypertext."

36. Cox, "Hypermedia Library Guides for Academic Libraries on the World Wide Web"; Heaton, Kazuba, and D'Agostino, "A HyperCard Program to Assist Users at a Self-help Periodicals Information Center."

37. Cox, "Hypermedia Library Guides for Academic Libraries on the World Wide Web"; Creanor, Durndell, and Primrose, "Library and Study Skills Using Hypertext"; Pask, "ComputerAssisted Instruction for Basic Library Skills"; Shill, "Bibliographic Instruction."

38. Creanor, Durndell, and Primrose, "Library and Study Skills Using Hypertext"; Richardson, "Computer-Assisted Library Instruction?"; Shill, "Bibliographic Instruction."

39. Cox, "Hypermedia Library Guides for Academic Libraries on the World Wide Web."

40. Janice Simmons-Welburn, "Alternative Models for Instruction in the Academic Library: Another View of the Upside of Downsizing," in The Upside of Downsizing: Using Library Instruction to Cope, ed. Cheryl LaGuardia, Stella Bentley, and Janet Martorana (New York: Neal-Schuman, 1995), 15-23.

41. Ibid., 21.

42. Shill, "Bibliographic Instruction."

43. Cox, "Hypermedia Library Guides for Academic Libraries on the World Wide Web"; Pask, "Computer-Assisted Instruction for Basic Library Skills."

44. Creanor, Durndell, and Primrose, "Library and Study Skills Using Hypertext"; Richardson, "Computer-Assisted Library Instruction?"

45. Pask, "Computer-Assisted Instruction for Basic Library Skills."

46. Cox, "Hypermedia Library Guides for Academic Libraries on the World Wide Web."

47. Kaplowitz and Contini, "Computer-Assisted Instruction"; Melick, "Changing to a Hypertext-based Library Instruction Program Using Inexpensive Software for IBM Compatibles"; Richardson, "Computer-Assisted Library Instruction?"; Rumsey, "HyperCard for Bibliographic Instruction"; Rama Vishwanatham, Walter R. Wilkins, and Thomas Jevec, "The Internet as a Medium for Online Instruction," College E Research Libraries 58 (Sept. 1997): 433-44.

48. Michael O. Engle, "Using World Wide Web Software for Reference and Instruction," Internet Reference Services Quarterly 1, no. 2 (1996): 8.

49. Andrew Cox, "Using the World Wide Web for Library User Education: A Review Article," Journal of Librarianship and Information Science 29 (Mar. 1997): 39-43.

50. Ibid. 
51. Bourne, "Computer-Assisted Instruction, Learning Theory, and Hypermedia," 168.

52. Ibid.

53. Kaplowitz and Contini, "Computer-Assisted Instruction"; Pask, "Computer-Assisted Instruction for Basic Library Skills"; Richardson, "Computer-Assisted Library Instruction?"

54. Pask, "Computer-Assisted Instruction for Basic Library Skills."

55. Kaplowitz and Contini, "Computer-Assisted Instruction"; Pask, "Computer-Assisted Instruction for Basic Library Skills."

56. Germain, Jacobson, and Kaczor, "A Comparison of the Effectiveness of Presentation Formats for Instruction"; Pask, "Computer-Assisted Instruction for Basic Library Skills"; Richardson, "Computer-Assisted Library Instruction?"

57. Vishwanatham, Wilkins, and Jevec, "The Internet as a Medium for Online Instruction."

58. Richardson, "Computer-Assisted Library Instruction?"

59. Ibid., 47.

60. Cox, "Using the World Wide Web for Library User Education."

61. V. Lonnie Lawson, "Using a Computer-Assisted Instruction Program to Replace the Traditional Library Tour: An Experimental Study," RQ 29 (fall 1989): 71-79.

62. Vander Meer and Rike, "Multimedia."

63. Kaplowitz and Contini, "Computer-Assisted Instruction."

64. Germain, Jacobson, and Kaczor, "A Comparison of the Effectiveness of Presentation Formats for Instruction."

65. Ibid.; Kaplowitz and Contini, "Computer-Assisted Instruction"; Vander Meer and Rike, "Multimedia."

66. Lawson, "Using a Computer-Assisted Instruction Program to Replace the Traditional Library Tour."

67. Kaplowitz and Contini, "Computer-Assisted Instruction."

68. Research Committee, Library Instruction Round Table, American Library Association. Evaluating Library Instruction: Sample Questions, Forms, and Strategies for Practical Use, ed. Diana D. Shonrock (Chicago: ALA, 1996).

69. Kaplowitz and Contini, "Computer-Assisted Instruction"; Melick, "Changing to a Hypertextbased Library Instruction Program Using Inexpensive Software for IBM Compatibles"; Richardson, "Computer-Assisted Library Instruction?"; Rumsey, "HyperCard for Bibliographic Instruction"; Vishwanatham, Wilkins, and Jevec, "The Internet as a Medium for Online Instruction."

70. Miller, "Self-paced Tours in the Electronic Library." 